\title{
Content Characteristics of Mobile-linked Online Games and Linkage Model for MMOPRG-based Mobile Online Games
}

\author{
Hui Beom Yu and Jung Hwan Sung \\ Information Science Department, Songsil Univ., Sangdo 1-dong, Dongjak-gu, \\ Seoul, Korea \\ cutyboyjin@crossdesignlab.com,artbysung@crossdesignlab.com
}

\begin{abstract}
Along with the growth of the mobile game market, various and significant changes are taking place in terms of the game development environment, open policy, and genre. As one such change, "mobile-linked online games," i.e., mobile games linked with online PC games, have appeared. The term linkage indicates that games, which were once independent of each other, have become connected through the linking of game data across mobile, console, PC, and Web platforms; this goes beyond the concept of a crossplatform, in which the same games are simply built on different platforms. A mobile platform developed for linking is obviously central to mobile-linked online games. Many linked online games are being produced on the mobile platform. However, in the case of online PC games, whose contents were originally developed for the PC platform, such as MMORPG (Massively Multiplayer Online Role-Playing Games), the method and purpose of their linkage differ. This paper systematically classifies mobile-linked online games into three types: mid-core, hardcore, and casual games. In addition, this paper reveals the characteristics and purpose of the online linking method for mobile-linked MMORPGs (a MMOPRG is a typical hardcore type game). Furthermore, the mobile linkage model for MMORPGs is defined by the PVE and PVP contents.
\end{abstract}

Keywords: online game, mobile game, MMORPG, casual game, Flow, mobile-linked online game

\section{Introduction}

Popularization of smartphones and the consequent expansion of the mobile game market has created new game markets while also influencing existing console and PC games. However, these markets have shown strong complementary tendencies, instead of engaging in competition. This effect is demonstrated most directly in the case of online game linkages. In early 2000s, incipient mobile-linked online games are released. But these titles can count on the hand. Most available titles are launching since then 2010s. In the current study, we aim to explore the state of the linkage market for the MMORPGalso known as the "hardcore" games among the many mobile-linked games-as well as effective linkage methods for MMORPGs. For this purpose, the developmental processes behind mobile-linked online games will be examined and current mobile linkage methods for online games will be sorted by type. In addition, the significance of mobile linkage services will be examined through the analysis of MMORPG games that currently provide mobile-PC linkage services. Based on result of the analyses draw up a mobile linkage model of hardcore Games (MMORPG).

\section{Mobile-Linked Online Games}

While previous game markets maintained an exclusive position towards doubleplatforming, a new market for connective and non-restrictive gaming has been forming 
since the advent of mobile games. It is now possible to play the same game title across all OS types and consoles, and games based on double platforms are sharing IPs, thereby allowing different versions of the said games to develop. After the explosive growth of the mobile game market, there have been new expectations for mobile-linked online games, and since 2010, a number of online games have been developed to allow mobile linkages.

\subsection{Classification of the Types of Mobile-Linked Online Games}

In studies published before the generalization of the concept of mobile-linked online games, mobile-linked games were classified as using 1) direct or 2) indirect linkages, according to game linkage elements, or as operating based on 1) self-transmission, 2) verification codes, or 3) mixtures, according to physical linkage methods. However, this classification is influenced by current infrastructures of wireless networks and is not very significant. We sought to classify mobile-linked online games according to game content instead.

Table 1. Classification of the Types of Mobile-linked Online Games

\begin{tabular}{|c|c|c|}
\hline Type & Characteristics & Example \\
\hline Mid-core & $\begin{array}{l}\text { Games that aim for the materialization of hardcore elements within } \\
\text { the mobile environment. } \\
\text { PS titles in multiplatform format on Play Station Portable } \\
\text { Consoles (PSP) that use one user account to access the game on } \\
\text { different environments, such as PCs, mobile devices, and Internet } \\
\text { browsers. }\end{array}$ & $\begin{array}{l}\text { Epic of the Three } \\
\text { Kingdoms, } \\
\text { Arcane Legends }\end{array}$ \\
\hline Hardcore & $\begin{array}{l}\text { Hardcore games produced for existing desktop environments. } \\
\text { Despite sharing the same login information of a single account } \\
\text { with mobile platforms, only a part of the game content is } \\
\text { transferred to mobile platforms, or separate content specific to } \\
\text { mobile platforms is provided. }\end{array}$ & $\begin{array}{l}\text { Lineage \& Lineage } \\
\text { Heist, WoW \& Mobile } \\
\text { Armory App, } \\
\text { ArcheAge \& } \\
\text { ArcheVille }\end{array}$ \\
\hline Casual & $\begin{array}{l}\text { Games that reflect the IP of existing well-known games in separate } \\
\text { mobile (and mostly casual) formats. Rewards obtained through } \\
\text { gameplay are partly shared with the PC game. }\end{array}$ & $\begin{array}{l}\text { Dungeon Fighter \& } \\
\text { Puzzle Dungeon } \\
\text { Fighter }\end{array}$ \\
\hline
\end{tabular}

\subsection{Classification of the Types of Mobile-Linked Online Games}

In studies published before the generalization of the concept of mobile-linked online games, mobile-linked games were classified as using 1) direct or 2) indirect linkages, according to game linkage elements, or as operating based on 1) self-transmission, 2) verification codes, or 3) mixtures, according to physical linkage methods. However, this classification is influenced by current infrastructures of wireless networks and is not very significant. We sought to classify mobile-linked online games according to game content instead.

Table 2. Mobile-linked Content and Characteristics of MMORPG

\begin{tabular}{|l|l|c|}
\hline \multicolumn{1}{|c|}{ Name(PC/Mobile) } & \multicolumn{1}{|c|}{ Linked content } & Characteristic \\
\hline $\begin{array}{l}\text { World of Warcraft / } \\
\text { World of Warcraft Armory }\end{array}$ & $\begin{array}{l}\text { Some social functions, such as guild contents and the } \\
\text { messenger, and a separate auction room for the mobile } \\
\text { app }\end{array}$ & $\begin{array}{c}\text { Information } \\
\text { Extraction Type }\end{array}$ \\
\hline Lineage / Lineage Heist & The Dream Island, a mobile-only field & $\begin{array}{c}\text { Space Expansion } \\
\text { Type }\end{array}$ \\
\hline $\begin{array}{l}\text { Granado Espada / } \\
\text { GE Battle }\end{array}$ & $\begin{array}{l}\text { Provides mobile-only battle content between game } \\
\text { characters }\end{array}$ & $\begin{array}{c}\text { Space Expansion } \\
\text { Type }\end{array}$ \\
\hline $\begin{array}{l}\text { Granado Espana / } \\
\text { Gemocon }\end{array}$ & $\begin{array}{l}\text { Character's fields are controlled by Cloud-like } \\
\text { methods (actual graphic calculations are done in the } \\
\text { server while the control point is remotely maneuvered } \\
\text { in the mobile environment) }\end{array}$ & $\begin{array}{c}\text { Space Expansion } \\
\text { Type }\end{array}$ \\
\hline
\end{tabular}




\begin{tabular}{|l|l|c|}
\hline $\begin{array}{l}\text { Tibia Me / } \\
\text { Tibia Me(mobile) }\end{array}$ & $\begin{array}{l}\text { The same field and content are provided for PCs and } \\
\text { mobile devices, but graphics and UI are simplified in } \\
\text { mobile form }\end{array}$ & $\begin{array}{c}\text { Synchronization } \\
\text { Type }\end{array}$ \\
\hline $\begin{array}{l}\text { Blade \& Soul / } \\
\text { Blade \& Soul App }\end{array}$ & $\begin{array}{l}\text { Some social functions, such as guild contents and the } \\
\text { messenger, and a separate auction room for the mobile } \\
\text { app }\end{array}$ & $\begin{array}{c}\text { Information } \\
\text { Extraction Type }\end{array}$ \\
\hline $\begin{array}{l}\text { AcheAge / } \\
\text { ArcheVille }\end{array}$ & $\begin{array}{l}\text { Realization of actual game's farming content into a } \\
\text { casual mobile game; the same content is reconstructed } \\
\text { specially for mobile devices }\end{array}$ & $\begin{array}{c}\text { Space Expansion } \\
\text { Type }\end{array}$ \\
\hline $\begin{array}{l}\text { EoS Online / } \\
\text { EoS Online App }\end{array}$ & $\begin{array}{l}\text { Some social functions, such as guild contents and the } \\
\text { messenger, and a separate auction room for the mobile } \\
\text { app }\end{array}$ & $\begin{array}{c}\text { Information } \\
\text { Extraction Type }\end{array}$ \\
\hline $\begin{array}{l}\text { Dragon Nest / } \\
\text { Dragon Nest App }\end{array}$ & $\begin{array}{l}\text { Some social functions, such as guild contents and the } \\
\text { messenger, and a separate auction room for the mobile } \\
\text { app }\end{array}$ & $\begin{array}{c}\text { Information } \\
\text { Extraction Type }\end{array}$ \\
\hline
\end{tabular}

Table 2 lists leading MMORPG games and characteristics of their mobile-linked content. The linked content can be organized into three types in general. The information extraction type refers to a partial linkage, characterized by social functions such as economic activity within the game, chat, and schedule management, and only the information within the game is shared.

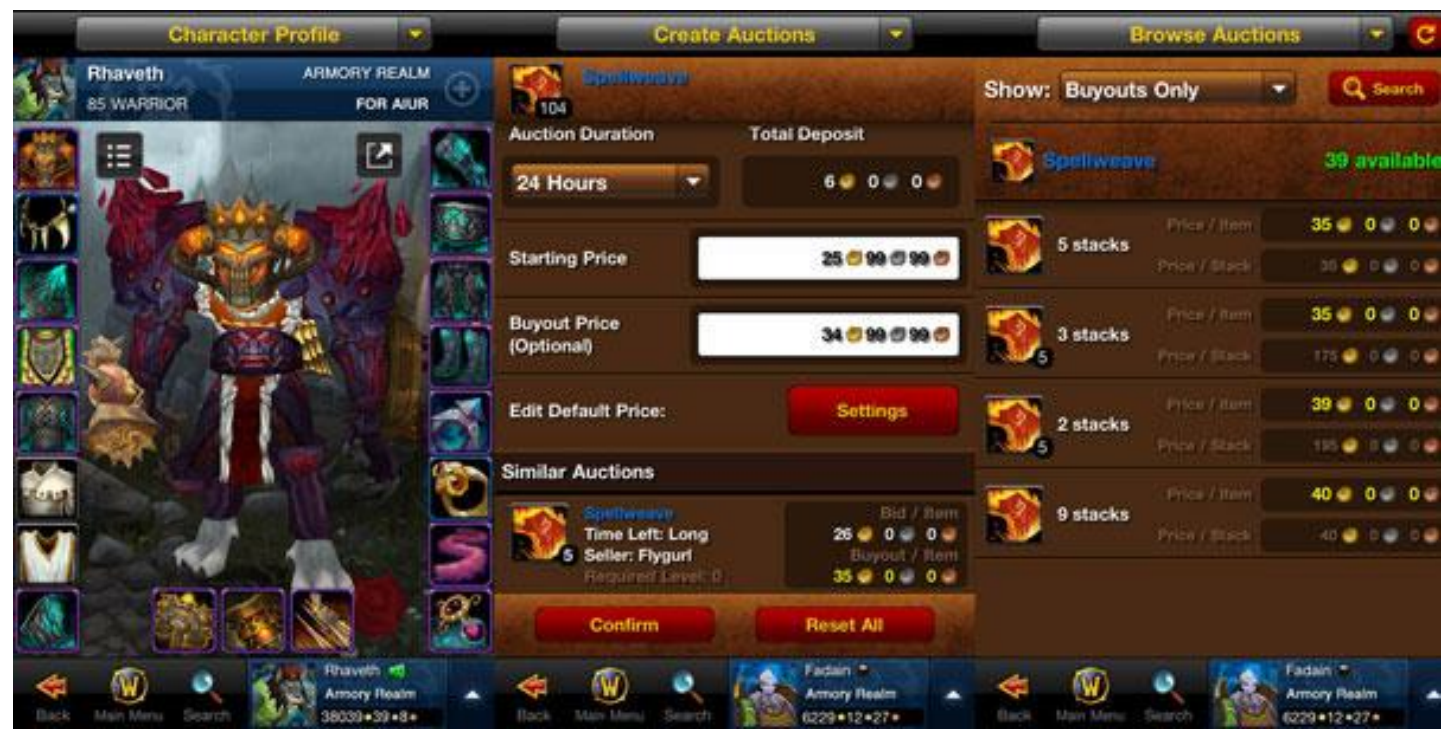

Figure 1. Wow Amory App, Information Extraction Type

Wow (World of Warcraft) 'Amory app' is typical example of information extraction type. 'Amory app's UI \& graphics designed for provide useful information to players not an interesting game play. Actually, this application is not a game by itself. It's closer with a social network application than a network game. However, game experiences to be strongly influenced by application activity. The space expansion type links new content that does not exist in desktop platforms, thus providing mobile-only fields or game content. For example, 'The Island of Oneiric' which of Lineage haste's main contents field available only in mobile platform. This paly field design for only mobile users, also game play different with PC platforms that. 


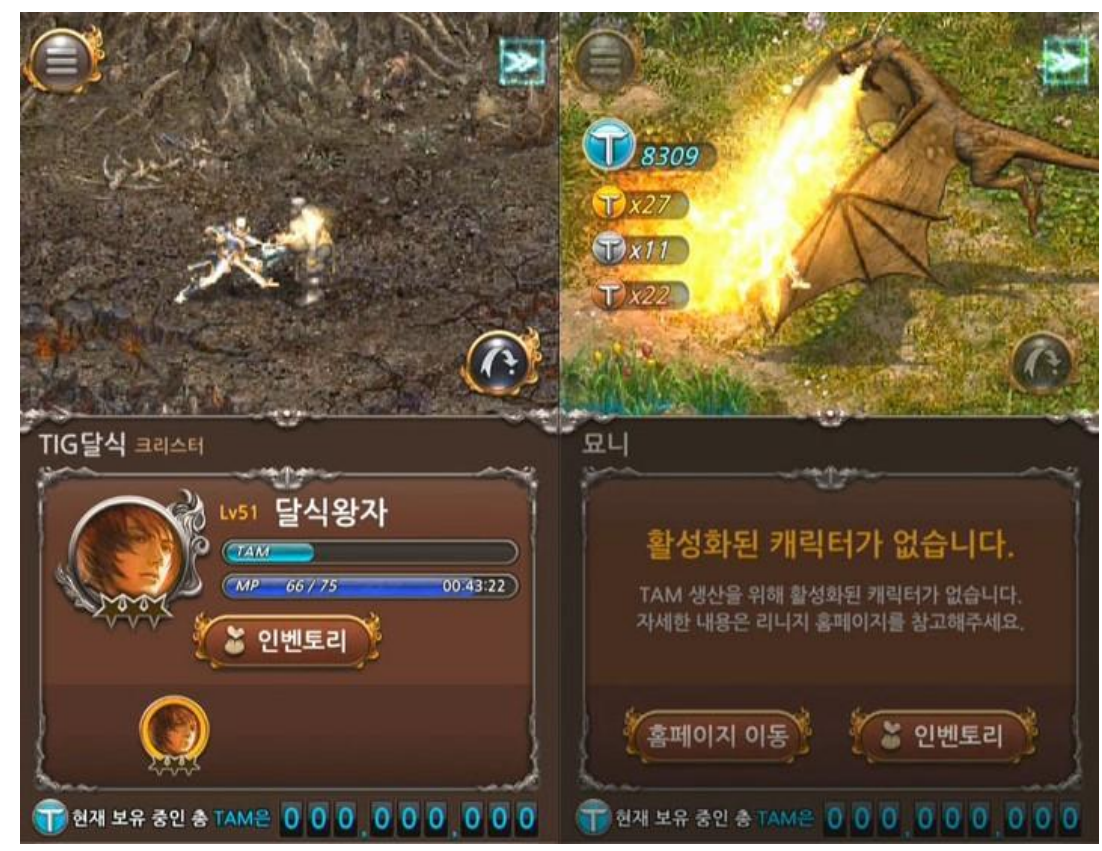

Figure 2. Linege Hast, Space Extention Type

Finally, the platform-specific type shares all content and information, though in forms specifically adapted to each platform. Thus, depending on the platform, the same game content may have lower resolution graphics or a different UI. 'Tibia Me' developed for PC and mobile. Each platform's game share every information even game field but UI and graphic quality are different. For example, PC version game FOV (focus of view)is more wide than mobile version, PC version character moving mechanism(UI) is more intuitively be caused by abundant hardware resources.
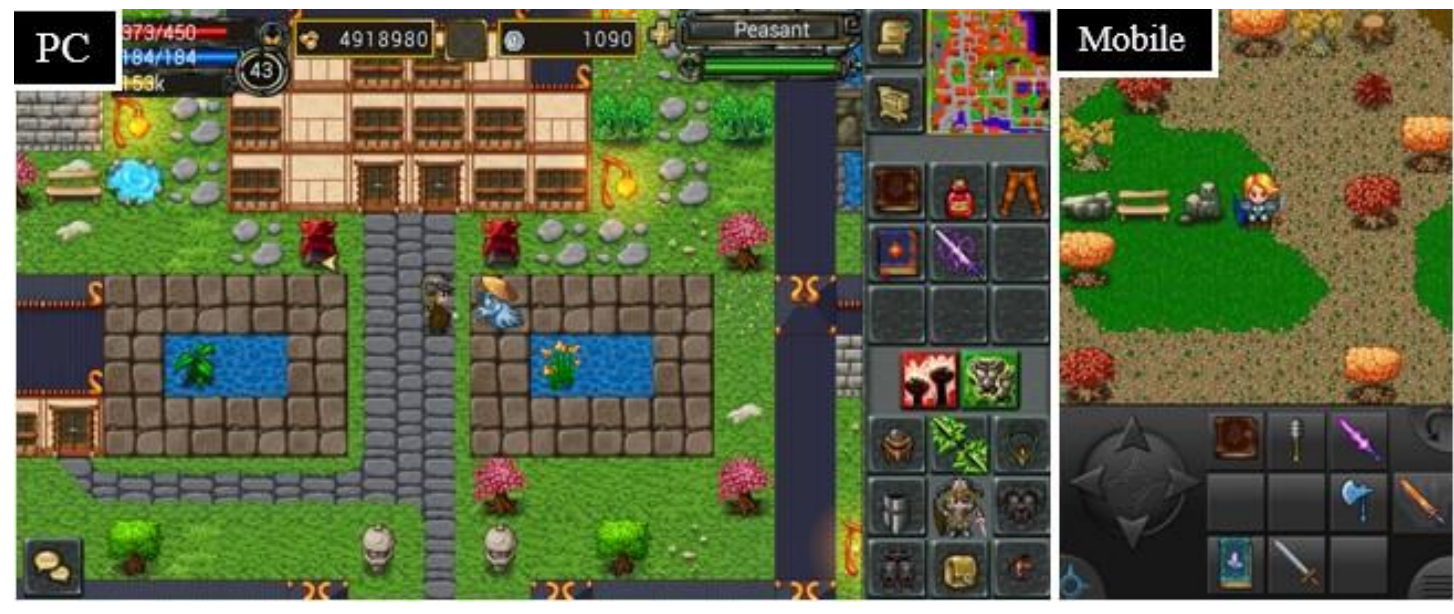

Figure 3. Tibia Me, platform-specific Type

On the whole, very few mobile games now retain characteristics of their original hardcore counterparts, as the absolute quantity of game contents has decreased and the gameplay has become simplified. Nevertheless, this doesn't mean that they have become casual games. Jesper Juul compared casual and hardcore games and defined five elements that constitute casual games. 
Table 3. Elements of Casual Game

\begin{tabular}{|l|l|}
\hline \multicolumn{1}{|c|}{ Elements } & \multicolumn{1}{c|}{ Description } \\
\hline Subject matter & $\begin{array}{l}\text { Casual games are usually based on entertaining subject matter. } \\
\text { Usability }\end{array}$ \\
$\begin{array}{l}\text { Casual games assume that the user does not have customary mobile game } \\
\text { knowledge. Also, casual game designs boast high usability. }\end{array}$ \\
\hline $\begin{array}{l}\text { Possibility of } \\
\text { stopping }\end{array}$ & $\begin{array}{l}\text { Casual games are designed to induce instantaneous immersion into the game. Casual } \\
\text { games are designed to allow one to stop playing whenever desired. }\end{array}$ \\
\hline $\begin{array}{l}\text { Difficulties and } \\
\text { punishment }\end{array}$ & $\begin{array}{l}\text { Many parts of the game do not require replaying. In cases of failure, punishments } \\
\text { are lenient. }\end{array}$ \\
\hline Richness & $\begin{array}{l}\text { Excessively positive feedback is supplied to all successful actions performed by the } \\
\text { player. Casual game designs are highly positive in terms of rewards. }\end{array}$ \\
\hline
\end{tabular}

Based on these five elements, mobile-linked MMORPG-based games are closer to casual games in form, but in terms of subject matter and usability, they have not diverted from hardcore games in principle. In terms of richness, in particular, results of interactions are made to be quantitatively verifiable. This double identity in PC and mobile environments makes sense only when viewed from a singular and linear perspective. Mobile gameplay consists of earning achievements; the said achievements are aggregated for desktop gameplay. That is to say, a repetitive cycle of production in mobile environments and collection in desktop environments comes into being. In a series of studies that analyzes games through Flow Theory, this sort of cycle configuration is referred to as a positive addiction model.

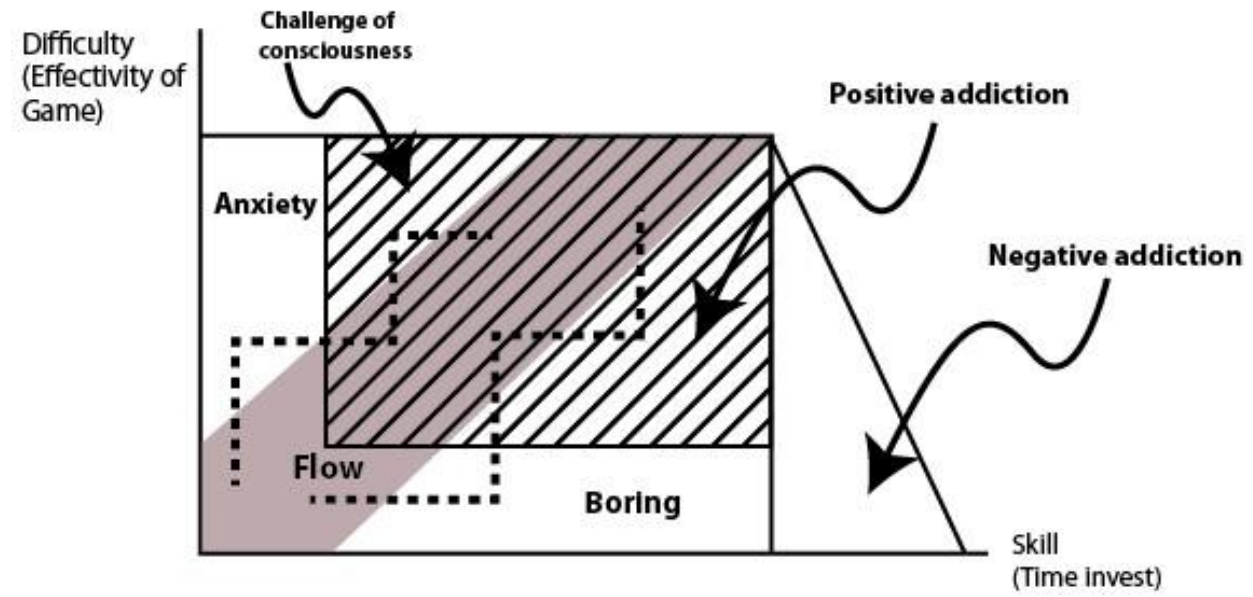

Figure 4. Positive Addiction Model

As shown in Figure 1, positive addiction is an optimized experience, defined as the inevitable opportunistic cost paid to pursue flow (or the flow state). That is to say, gamers who reach a certain level of performance invest a certain amount of time in order to experience a higher flow state. Here, the relationship between temporal investment and high flow states is of the same configuration as the aforementioned cycle for mobilelinked games, and its significance is thus explained. In other words, hardcore online mobile games resolve the spatial limitations of the opportunistic costs paid by hardcore game players via certain characteristics of mobile platforms.

\section{A Mobile Linkage Model of Hardcore Games}

We have already explained the significance of linkages through the example of mobilelinked hardcore games and analysis of their forms. Based on the said findings, we should be able to define a mobile linkage model for hardcore games. The core concept of the linkage model is how one might select which content to extract and apply to mobile 
platforms. Previously, the linked contents applied to mobile platforms were defined as the opportunistic cost paid by players to pursue a higher flow state. This type of content requires constant and repetitive temporal investment as well as low technical difficulty. In terms of in-game contents, the aforementioned contents may include extracting resources, increasing the value of in-game resources through auctions, or obtaining certain experience levels or items via games that are composed of simpler rules and lower difficulty than those found in PC games. The characteristics of these contents may thus be said to be productive in form, as according to the purpose of the gameplay.

\subsection{The Productive Form of PVE Contents}

As implied by the aforementioned definitions of contents in productive form and the example of mobile-linked hardcore games, most mobile-linked contents are playerversus-environment (PVE) contents. Components of these contents are already productive by principle. Even when content is not directly related to productive activities, as in extraction, collection, or financial transactions, all activities that aim to obtain a higher level of experience in the desktop version of the game may be considered to be productive activities. For instance, mobile-linked games of the space-expansion type consist mostly of battle- or expedition-related contents. However, the main purpose of the gameplay for players who utilize these contents is more the production of resources and items through constant hunting than pure, content-driven entertainment. In this scenario, even battlerelated contents may be considered to be productive activities.

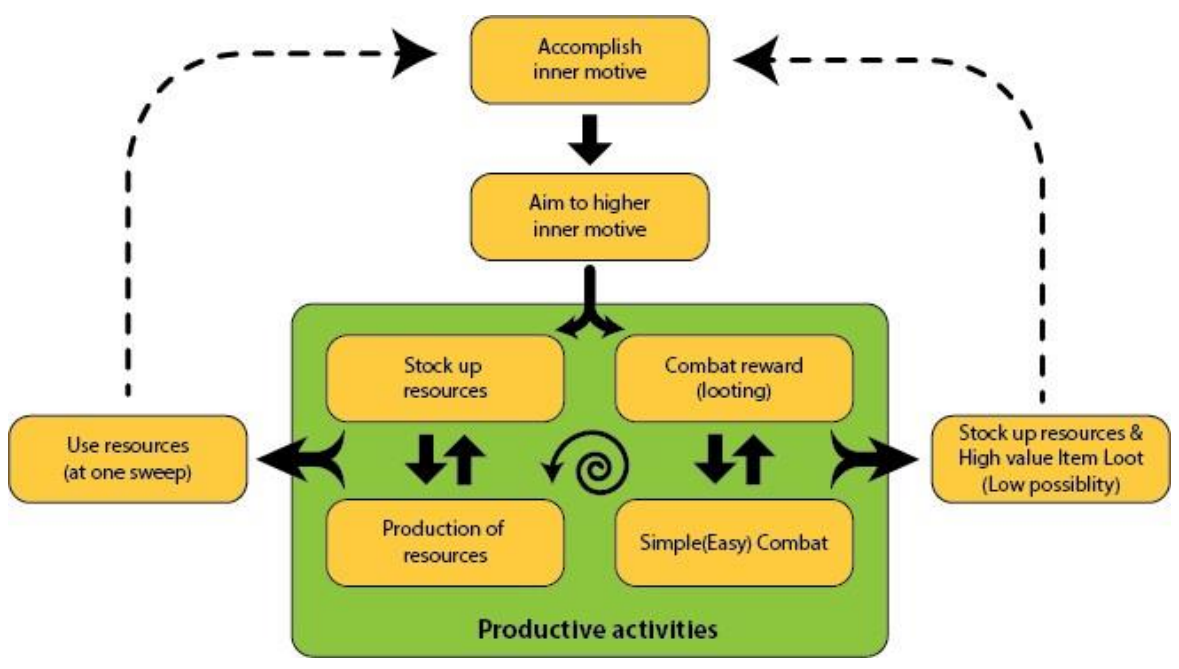

Figure 5. Productive Activity Model of PVE Contents

\subsection{The Productive Form of PVP Contents}

As for player-versus-player (PVP) content, no definition of productive activities can be directly applied in order to determine its productive form, as it is practically impossible to measure opportunistic costs in player-player interactions. However, even in the case of PVP content, productive activities may emerge if PVP contents are organized in such a way as to maintain a regular form and ensure that a majority of players follow certain rules. This should be understood as a concept relating to the player's role, where the player assumes the role of producer, rather than relating to the content itself. In largescale PVP group contents, such as those provided by siege warfare within Lineage, there are players who prepare necessary war supplies or take on the roles of low-ranking characters that make up the basic battle force, even when these roles are not crucial in determining a team's success or failure in the said warfare. Thus, players' sole motivation for carrying out such roles may be the eventuality of victory for their team and the 
rewards that follow, even when this means that they will not derive enjoyment from the siege warfare content. That is to say, productive activity within PVP contents may be the performance of a productive role.

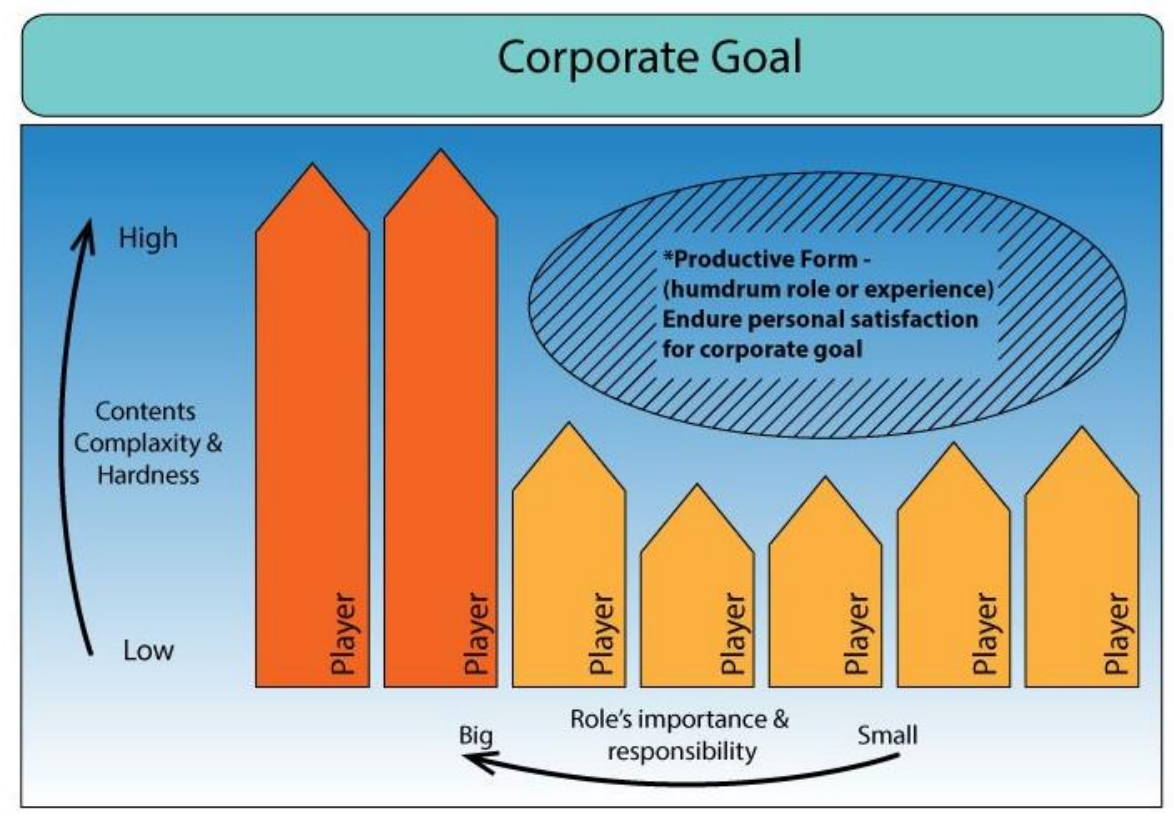

Figure 6. Productive Activity Model of PVP Contents

\section{Conclusion}

Mobile-linked online games are classified into three types, mid-core, hardcore, and casual games, and among them, hardcore games represented by MMOPRGs have been examined; it was shown that the mobile linkage form of hardcore games differs from that of mobile-oriented mobile-linked online games. By examining the contents of mobilelinked MMOPRGs, which is a typical type of hardcore game, the significance of linking hardcore-type mobile online games has been determined. Conclusively, we found that the purpose of mobile-linked hardcore online games is to solve the spatial limitation of the opportunistic cost paid by players via characteristics of the mobile platform. Based on the importance of linkages, we also constructed a linkage model for hardcore games by dividing it in terms of PVE and PVP contents. In defining the linkage model, PVE contents and their role in the model were easy to recognize within the example concerning mobile-linked games, but PVP contents were harder to define within the model, as they lack empirical examples and because the definition of productive activities ultimately depends on the intention of each player. This suggests that a more quantitative evaluation model is needed to verify the aforementioned statements. On the other hand, it shows the possibility that the linkage model of PVP contents can lead to the creation of a new type of mobile linked game. As a follow-up study, such an evaluation model will be derived on the basis of the flow theory, and through this model, the linkage model of PVP content is expect to become more concrete.

\section{References}

[1] M. Csikszentmihalyi, "Flow: The Psychology of Optimal Experience", Harper \& Row, Publisher, New York (1990).

[2] J. Juul, "A Casual Revolution: Reinventing Video Games and Their Players”, MIT Press, Cambridge (2010).

[3] D. L. Hoffman and T. P. Novak, "Marketing in Hypermedia Computer Mediated Environments: A Structual Modeling Approaches", Journal of Marketing, vol. 60, (1996), pp. 50-68. 
[4] S.-K. Lee, "Positive Addiction of Computer (On -line) Games", Journal of Cyber communication Academic Society, Cyber communication Academic Society, vol. 23, (2007), pp. 149-181.

[5] Baharom, S. Nizar, W. H. Tan and I. M. Zaffwan, "Emotional Design for Games: A Framework for Player-Centric Approach in the Game Design Process", International Journal of Multimedia \& Ubiquitous Engineering, Science \& Engineering Research Support society, (2014), vol. 10, pp. 387.

[6] W.-T. Lim, M.-B. Yang and S. B. Kim, "A Novel Card-based Information Security Game Development on SNS”, IJSIA, vol. 7, (2013), pp. 127-136.

[7] S. Moon, S. Lee, S. Kim, H. Hyun and S. Chin, "Cinematic Wound Synthesis Optimized for Real-time Gameplay", IJSEIA, vol. 7, (2013), pp. 221-228.

[8] Y.-J. Lee, "The Analysis of Brand Effect Appearing on 3D Computer Game, IJMUE, vol. 8, (2013), pp. 197-206.

[9] J. W. Oak and J. H. Bae, "Development of Smart Multiplatform Game App using UNITY3D Engine for CPR Education”, IJMUE, vol. 9, (2014), pp. 263-268.

[10] H. Park, "Relationship between Motivation and Student's Activity on Educational Game", IJGDC, vol. 5, (2012), pp. 101-114.

\section{Authors}

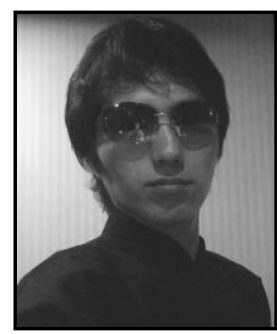

Hui-Beom Yu, he received the B.S. degree in Contents Engineering from Soongsil University in 2007. His research interests include conversions environment, digital art and contents.

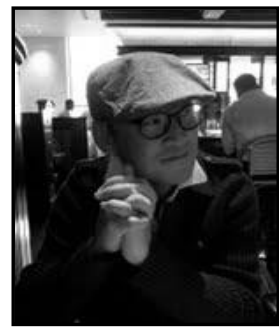

Jung-Hwan Sung, he received the M.F.A degree in Computer Graphics and Interactive media at Pratt Institute in 2000. He received a Ph.D. degree in philosophy of art from Chung-Ang University. His research interests include Storytelling, Interactive Design, and Interactive media art. 